\title{
A Simple Strategy in Avulsion Flap Injury: Prediction of Flap Viability Using Wood's Lamp Illumination and Resurfacing with a Full-thickness Skin Graft
}

\author{
Hyoseob Lim¹, Dae Hee Han², Il Jae Lee², Myong Chul Park² \\ ${ }^{1}$ Department of Plastic and Reconstructive Surgery, Hallym University Sacred Heart Hospital, Anyang; ${ }^{2}$ Department of Plastic and \\ Reconstructive Surgery, Ajou University Hospital, Ajou University School of Medicine, Suwon, Korea
}

Background Extensive degloving injuries of the extremities usually result in necrosis of the flap, necessitating comprehensive skin grafting. Provided there is a sufficient tool to evaluate flap viability, full-thickness skin can be used from a nonviable avulsed flap. We used a Wood's lamp to determine the viability of avulsed flaps in the operation field after intravenous injection of fluorescein dye.

Methods We experienced 13 cases during 16 months. Fifteen minutes after the intravenous injection of fluorescein dye, the avulsed skin flaps were examined and non-fluorescent areas were marked under Wood's lamp illumination. The marked area was defatted for fullthickness skin grafting. The fluorescent areas were sutured directly without tension. The nonfluorescent areas were covered by defatted skin. Several days later, there was soft tissue necrosis within the flap area. We measured necrotic area and revised the flap.

Results Among all the cases, necrotic area was $21.3 \%$ of the total avulsed area. However, if we exclude three cases, one of a carelessly managed patient and two cases of the flaps were inappropriately applied, good results were obtained, with a necrotic area of only $8.4 \%$. Eight patients needed split-thickness skin grafts, and heel pad reconstruction was performed with free flap.

Conclusions A full-thickness skin graft from an avulsed flap is a good method for addressing aesthetic concerns without producing donor site morbidity. Fluorescein dye is a useful, simple, and cost-effective tool for evaluating flap viability. Avulsed flap injuries can be managed well with Wood's lamp illumination and a full-thickness skin graft.

Keywords Tissue survival / Dermis / Skin transplantation / Soft tissue injuries / Extremities

Received: 11 Jun 2013 • Revised: 7 Aug 2013 • Accepted: 8 Aug 2013

pISSN: 2234-6163 • elSSN: 2234-6171 • http://dx.doi.org/10.5999/aps.2014.41.2.126• Arch Plast Surg 2014;41:126-132
Correspondence: Myong Chul Park Department of Plastic and Reconstructive Surgery, Ajou University Hospital, Ajou University School of Medicine, 164 World Cup-ro, Yeongtong-gu, Suwon 443-721, Korea Tel: +82-31-219-5614 Fax: +82-31-219-5610 E-mail:mpark@ajou.ac.kr

No potential conflict of interest relevant to this article was reported.

\section{INTRODUCTION}

Extensive degloving injuries of the extremities usually result from traffic accidents. The torsional and compressive forces affect different levels of the subcutaneous tissue and fascia, and can even separate and tear the skin from the deep fascia [1]. This can

Copyright $\odot 2014$ The Korean Society of Plastic and Reconstructive Surgeons

This is an Open Access article distributed under the terms of the Creative Commons Attribution Non-Commercial License (http://creativecommons.org/

licenses/by-nc/3.0/) which permits unrestricted non-commercial use, distribution, and reproduction in any medium, provided the original work is properly cited.

www.e-aps.org 
result in circumferential avulsion of the entire skin and subcutaneous tissue envelope of the leg. If there is sufficient blood supply, primary closure after minimal debridement is the common method of treatment. However, determining the viability of an avulsed flap is often difficult. If the demarcation of necrosis is revealed, other tissue is needed to cover the defect after serial debridements. Usually, a split-thickness skin graft (STSG) or free flap reconstruction is performed in the final step of coverage. STSG offers poor functional and cosmetic results, although it has good take rates under less favorable conditions [2]. Free flap reconstructions involve the sacrifice of a donor site. We tried to use a full-thickness skin graft (FTSG) of the devascularized avulsed flap immediately. After intravenous injection of fluorescein dye, the viability of the avulsed flap was determined using a Wood's lamp (Waldmann, Wheeling, IL, USA) illumination.

\section{METHODS}

From June 2010 until October 2011, we treated 11 patients (4 males, 7 females; average age, 52.4 years; range, 18-76 years) with degloving injuries of the lower extremities. One patient had three different avulsed flap injuries. In total, 13 operations were performed. Patients with severe open fractures were excluded.
Among the 11 patients, only one had metatarsal and phalangeal fractures, but the involved wound was in the heel pad.

In the operating room, adequate debridement of the damaged muscle or fascia was performed. After debridement and wound irrigation, two vials of fluorescein dye (Fluorescite 10\%, Alcon Korea, Seoul, Korea) were injected intravenously. After 15 minutes, the avulsed skin flaps were examined. Non-fluorescent areas were marked under Wood's lamp illumination (Fig. 1A). The marked area of the avulsed flap was defatted to be used for FTSG. The fluorescent areas were sutured directly without tension after minimal debridement. The non-fluorescent areas were covered by defatted skin (Fig. 1B). The compressive dressing on FTSG was maintained by vacuum-assisted closure (VAC, Fig. 1C). Postoperatively, lipo-prostaglandin E1 (Eglandin, Mitsubishi Tanabe Pharma Co., Hwaseong, Korea) was administered intravenously to augment the blood supply of non-defatted tissue for a week. Patients kept their leg elevated and immobilized for 2 weeks. The areas of skin necrosis were documented after several days. If a demarcated area of necrosis was noted, revision surgery was performed.

We documented the location of the wound, size of avulsed flap, size of defatted area, size of necrosis, and method of revision surgery for each patient.

\section{Fig. 1. Intraoperative photographs demonstrate the authors' methods}

(A) Under Wood's lamp illumination areas of fluorescence and nonfluorescence and mottled areas can be distinguished. (B) The flap of the non-fluorescent area is defatted to be used as FISG. (C) To prevent hematoma formation under FISG, VAC dressing is applied. FTSG, fullthickness skin graft; $V A C$, vacuum-assisted closure.
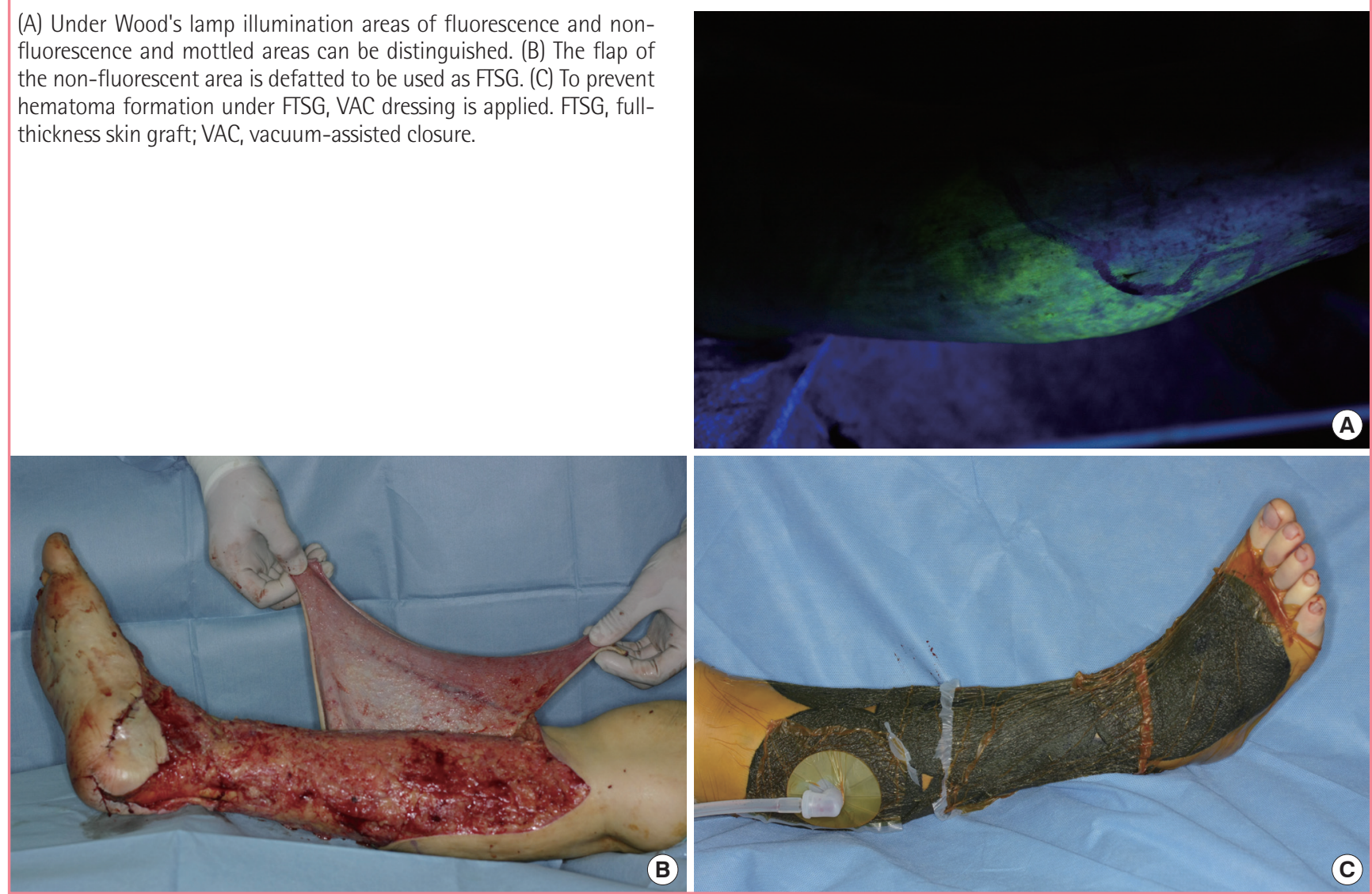
Table 1. Data from 13 surgeries of 11 avulsed flap patients

\begin{tabular}{|c|c|c|c|c|c|c|c|}
\hline No. & e $(y r) / S e x$ & Location & Avulsion $\left(\mathrm{cm}^{2}\right)$ & FTSG $\left(\mathrm{cm}^{2}\right)$ & Necrosis $\left(\mathrm{cm}^{2}, \%\right)$ & Revision & Remark \\
\hline 1 & $74 / F$ & Lower leg & 630 & 540 & $28(4.40)$ & STSG & Diabetes, hypertension \\
\hline 2 & $54 / \mathrm{M}$ & Lateral side of foot & 54 & 30 & $4(7.40)$ & STSG & Coumadization due to atrial fibrillation \\
\hline 3 & $61 / M$ & Dorsum of foot & 40 & 20 & $0(0.00)$ & None & \\
\hline 4 & $20 / F$ & Lower leg & 110 & 35 & $60(54.50)$ & STSG, acellular dermis & Muscle injury, pressure of splinta) \\
\hline 5 & $18 / F$ & Lower leg & 442 & 105 & $42(9.50)$ & STSG, acellular dermis & Muscle injury \\
\hline 6 & $68 / F$ & Dorsum of foot & 48 & 35 & $14(29.20)$ & STSG & Laceration on toes \\
\hline 7 & $76 / F$ & Dorsum of foot & 35 & 28 & $9(25.70)$ & STSG & Metatarsal fracture, phalangeal fracture \\
\hline 8 & $20 / F$ & Foot including heel & 150 & 56 & $70(46.70)$ & Free flap & Heel pad injurya) \\
\hline 9 & $73 / F$ & Lower leg & 88 & 56 & $20(22.70)$ & STSG & \\
\hline 10 & $44 / \mathrm{M}$ & Lower leg & 49 & 25 & $4(8.20)$ & Excision and repair & Marginal necrosis only \\
\hline 11 & $44 / \mathrm{M}$ & Medial side of foot & 60 & 12 & $0(0.00)$ & None & \\
\hline 12 & $44 / \mathrm{M}$ & Dorsum of foot & 25 & 16 & $3(12.00)$ & Excision and repair & Marginal necrosis only \\
\hline \multirow[t]{5}{*}{13} & $68 / \mathrm{M}$ & Posterior leg and calf & 400 & 400 & $200(50.00)$ & Meshed STSG & Severed skin, all necrosis from FTSGa) \\
\hline & & \multicolumn{6}{|l|}{ Total } \\
\hline & & \multirow{2}{*}{\multicolumn{2}{|c|}{$\begin{array}{l}\text { Mean value } \\
\text { Median value }\end{array}$}} & $63.70 \%$ & $21.30 \%$ & & \\
\hline & & & & $55.60 \%$ & $12.00 \%$ & & \\
\hline & & \multicolumn{2}{|c|}{ Except case 4,8 , and 13} & $58.90 \%$ & $8.40 \%$ & & \\
\hline
\end{tabular}

\section{RESULTS}

After the initial operation, the necrosis area averaged 21.3\% (Table 1). One patient did not require revision surgery. Another patient who had multiple wounds needed excision of necrotic skin and direct closure. Eight patients needed STSG and in one patient a free flap operation for heel pad reconstruction was performed. Most patients were satisfied with the cosmetic appearance of their grafts. However, patients who required a large area of STSG and who had received flap surgery were disappointed with their contour. One patient who underwent large mesh STSG at the popliteal area had limited range of motion of the knee.

\section{Case 1}

A 74-year-old woman encountered an avulsion injury to the right leg by a moving wheel, which resulted in a circumferential degloving of the skin from mid-thigh to the dorsum of the foot (Fig. 2A). The patient had been suffering from diabetes and hypertension for more than 10 years. After adequate debridement, the devascularized skin flap was defatted in attachment and used as a FTSG to cover the denuded area. Multiple but small areas of necrosis were found (Fig. 2B). At postoperative day 21, debridement and STSG were performed. At a follow-up 2 months postoperatively, the appearance was acceptable (Fig. 2C). At a follow-up at 13 months, no limitation of ambulation was evident.

\section{Case 2}

A 54-year-old man was run over by a car, which resulted in an avulsion of skin on the lateral surface of the right foot (Fig. 3A). The patient took warfarin regularly to prevent thromboembolism due to atrial fibrillation. After debridement, the devascularized skin flap was defatted and used as a FTSG. Necrosis was found at a small area where there was hematoma. A small STSG was done and recovery was uneventful. The appearance was good (Fig. 3B).

\section{Case 4}

A 20-year-old woman injured her right leg in a car accident. This was a circumferential degloving of the skin of the calf (Fig. 4A). The patient received FTSGs made from the avulsed flap for coverage. On postoperative day 6 , ongoing necrosis on the nondefatted area of the right calf was noted (Fig. 4B). Debridement was performed and VAC was applied. At postoperative day 23, final coverage was done with acellular dermis and STSG from a thigh. At a follow-up at 6 months, no limitation of ambulation was evident. The patient requested camouflage surgery of the STSG area (Fig. 4C).

\section{DISCUSSION}

Degloving injuries have become more common as the number of cars, and hence the number of car-related accidents, has increased. Specially, the running over of the lower extremities by a wheel 


\section{Fig. 2. Case 1: preoperative and postoperative photographs}

(A) Circumferential avulsed skin flap injury from the thigh to the dorsum of the foot was noted. (B) Multiple but small areas of necrosis were found. (C) An acceptable appearance was reported at a follow up at 2 months.
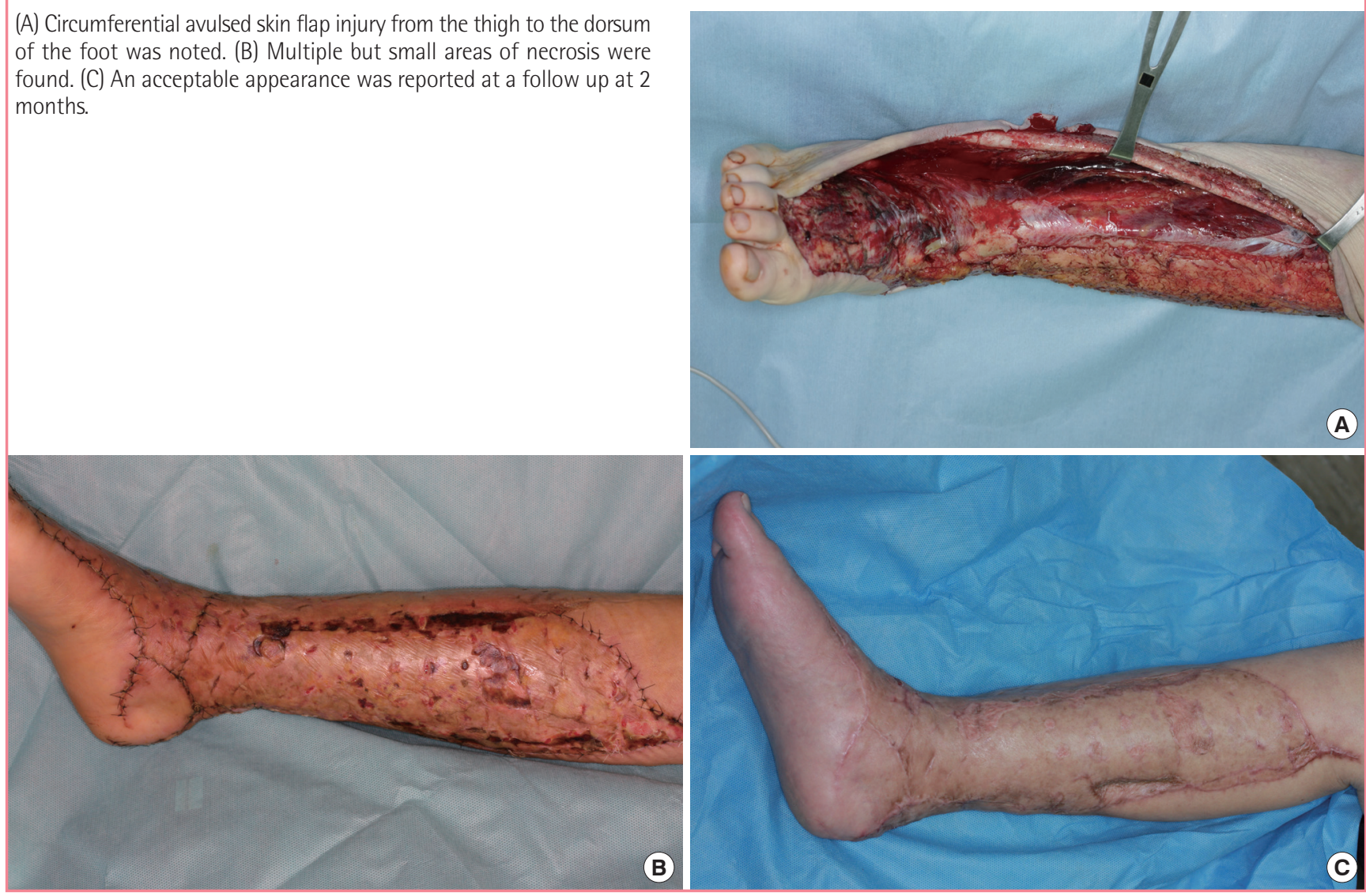

\section{Fig. 3. Case 2: preoperative and postoperative photographs}

(A) An avulsion flap injury was noted on the lateral surface of the foot. (B) Well recovered skin was found.
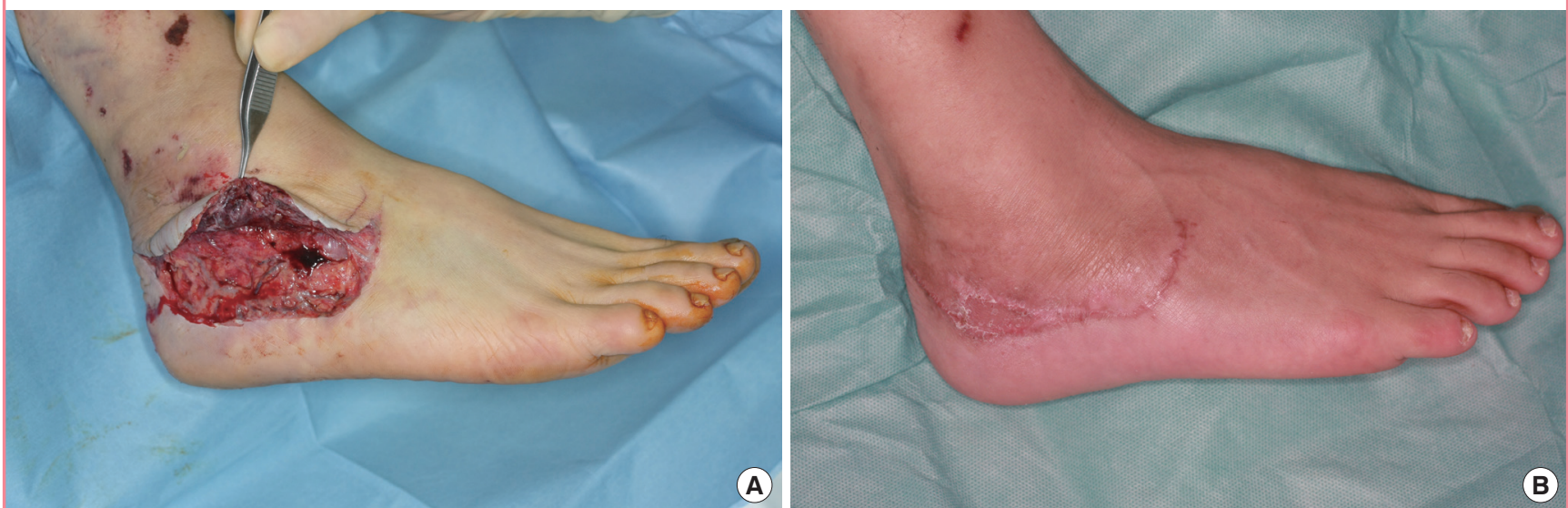

causes severe injuries, often involving crushing and devascularization of avulsed skin and subcutaneous tissue $[1,3]$. If there are combined open fractures, circulation of the avulsed flap is compromised more and the tissue condition can worsen during reduction of the fracture.

The first treatment goal is to retain the skin and underlying soft tissue and to support a better environment for the gliding of underlying muscles or tendons. Secondly, the contracture of the restored skin must be prevented to produce a functionally and cosmetically acceptable outcome. The donor site morbidity must be reduced after secondary surgery. The best results are obtained when the epidermis, dermis, and deep underlying layer remain intact. Primary closure without tension has been tried commonly in degloving injuries located under the 
Fig. 4. Case 4: preoperative and postoperative photographs

(A) A circumferential degloving injury was noted on the lower leg. (B)

A non-defatted area on dependent position changed to necrosis after

the 6th postoperative day. (C) No functional impairment was found,

but a depression was noted at the posterior calf.
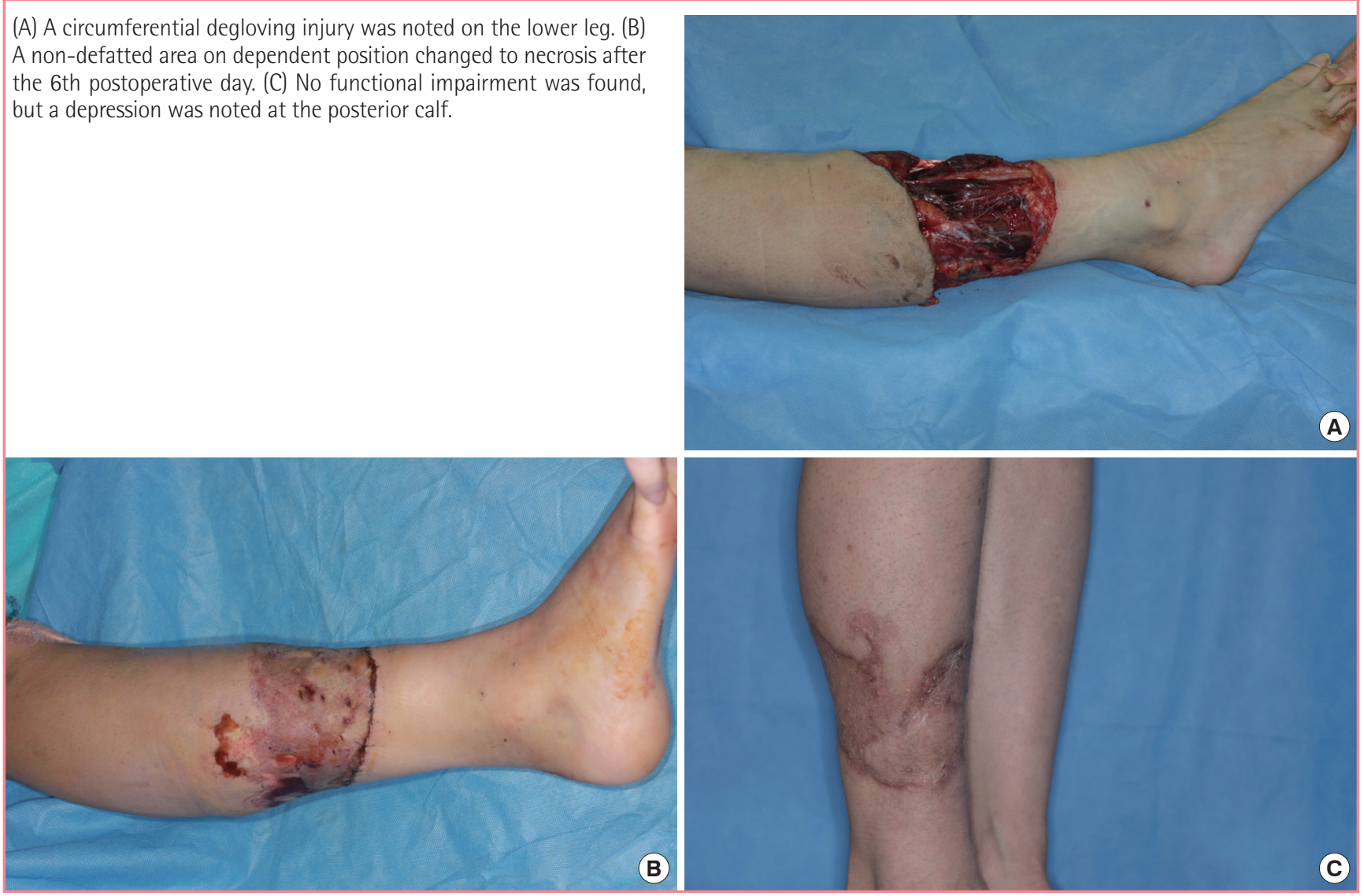

subcutaneous fat layer. However, in this situation, the skin and subcutaneous tissue are usually crushed during injury and serial debridements are needed to render the wound amenable for graft take. In seeking better solutions, taking a split-thickness skin graft from the avulsed flap $[4,5]$, salvaging the flap with arteriovenous shunting [6], or covering the defect by local or free flaps have been explored.

In degloving injuries in which the skin and subcutaneous tissues are avulsed and devascularized, the skin layer itself may be in good condition. Upon confirmation of destroyed skin, the next step is a skin graft or free flap coverage from a donor site. If the skin layer on a damaged subcutaneous fat layer survives, the skin can be used for FTSG. The FTSG overcomes both cosmetic and functional limitations of STSG. A FTSG shows almost the same quality as a fully, primarily vascularized skin flap with regard to texture, elasticity, and appearance. FTSGs do not have a high tendency to contracture and can grow in young patients $[2,7,8]$. A FTSG from an avulsed flap is not a new technique. Several reports about this procedure in degloving injuries have shown good results [1,7,9-13].

Determination of the viability of an avulsed flap is difficult. To evaluate flap viability, non-invasive techniques currently available include surface fluorometry, ultrasound, laser Doppler, photoplethysmography, temperature monitoring, and transcutaneous oxygen monitoring [14]. These techniques all involve sophisticated equipment that is not readily available and that is not ideal for assessing the viability of an acutely injured flap at the time of the initial operation. They are more suited to following flap viability postoperatively. Recently, some surgeons have ensured the accurate evaluation of flap viability with laser-assisted indocyanine green dye angiography using a SPY imaging system (LifeCell Corp., Branchburg, NJ, USA) [15,16]. However, this system is more expensive than a Wood's lamp. We used fluorescein dye with illumination for the intraoperative evaluation of skin flap viability. This approach proved accurate and can be done inexpensively to decrease donor site morbidity [17].

Florescent dye injection to evaluate flap viability was used as far back as the 19th century [18-20]. The accuracy can be improved with the use of a Wood's lamp [21], a device that emits ultraviolet light in the $365 \mathrm{~nm}$ range. This examination can strengthen or lessen the suspicion of a particular diagnosis, based on the color of fluorescence of the affected skin being illuminated. This method is simple, inexpensive, and non-invasive. It can be used in the operation field. This method has also been employed in skin 
sparing mastectomy. Singer et al. [22] described its use in 1978 as a predictor of mastectomy skin flap viability in conjunction with implant reconstruction, where it is crucial that any area of potential necrosis is excised. Revision surgeries were needed in $21.3 \%$ of the avulsion flaps. Possible causes of necrosis include incomplete debridement, skin damage, overestimation of flap viability, and inappropriate application of this method (e.g., plantar avulsed injury). Underlying tissue might not be clearly available for use as FTSG due to inadequate debridement. If the skin itself has been damaged, the surgeon must assess the viability of skin by direct visual examination. When there is nothing to lose, surgeons usually try to reattach the skin flap. This illumination method usually underestimates the survival of the flaps and the mottled area can survive after flap surgery or skin sparing mastectomy. Small areas of non-fluorescence $\left(<4 \mathrm{~cm}^{2}\right)$ can be used as a flap in skin sparing mastectomy [23]. However, we defatted the mottled area for FTSG because of the tendency toward necrosis at the margin of non-defatted areas in our experience. The tissue was severed and was different from the flap after a delay or skin-sparing mastectomy.

One patient (case 4) had a circumferential degloving injury of the lower leg, which required revision surgery because the previously-viable tissue had been killed from the pressure of the splint. Among 11 patients, a heel pad injury was addressed in one patient, who underwent free flap reconstruction as revision surgery. A plantar avulsion injury can be considered a specialized type [9]. We treated this patient the same as a usual avulsed flap injury. Revascularization of the plantar flap should be attempted at the first operation. Except for a careless case (case 4 splint-related pressure) and two cases of improper application (case 8 heel pad injury, case 13 extensive severed skin injury), revision surgery was required in only $8.4 \%$ of the areas.

One goal of surgery is to preserve more subcutaneous tissue. Some surgeons will defer the decision and choose delayed closure after demarcation of necrosis. Delayed closure or a secondlook operation can preserve more subcutaneous tissue but can also cause the need for a large amount of STSG. Concerning the flap delay phenomenon, numerous authors have reported similar findings using various techniques, corroborating these findings of vasodilation in the first 2 to 3 days after flap elevation $[24,25]$. Based on this knowledge, delay of the operation for 3 days may be helpful. However, in a degloving injury, the flap has experienced direct trauma and the vessels may have been injured. Therefore, the situation of the flaps is not the same. In a study concerning delayed full-thickness autografting of cryopreserved avulsed skin, the procedure was reported to be reasonable but the preservation of viable full-thickness skin did not last until demarcation of necrosis, and two or more opera- tions were necessary [2]. The amendment of this approach with a Wood's lamp test following the introduction of fluorescein dye can produce better results. If the accuracy of determination of tissue viability is perfect, there is no need for secondary surgery or possibility of functional or cosmetic impairment. To increase accuracy, reduce the cost, and simplify the tissue viability assessment, we introduced Wood's lamp illumination with fluorescein dye injection.

FTSG from an avulsed flap is a good method for addressing aesthetic concerns without donor site morbidity. Fluorescein dye is a useful, simple, and cost-effective tool to evaluate flap viability. The avulsed flap injury can be managed well with Wood's lamp illumination and FTSG.

\section{REFERENCES}

1. Jeng SF, Wei FC. Technical refinement in the management of circumferentially avulsed skin of the leg. Plast Reconstr Surg 1997;100:1434-41.

2. Nogueira A, Martinez MJ, Arriaga MJ, et al. Delayed fullthickness autografting of cryopreserved avulsed skin in degloving injuries of the extremities. Plast Reconstr Surg 2001; 107:1009-13.

3. Innis CO. Treatment of skin avulsion injures of the extremities. Br J Plast Surg 1957;10:122-40.

4. Zeligowski AA, Ziv I. How to harvest skin graft from the avulsed flap in degloving injuries. Ann Plast Surg 1987;19: 89-90.

5. Goris RJ, Nicolai JP. A simple method of taking skin grafts from the avulsed flap in degloving injuries. Br J Plast Surg 1982;35:58-9.

6. Hsu WM, Wei FC, Lin CH, et al. The salvage of a degloved hand skin flap by arteriovenous shunting. Plast Reconstr Surg 1996;98:146-50.

7. Huemer GM, Schoeller T, Dunst KM, et al. Management of a traumatically avulsed skin-flap on the dorsum of the foot. Arch Orthop Trauma Surg 2004;124:559-62.

8. Mc KD, Edgerton MT Jr. The surgical treatment of lymphedema of the lower extremities. Plast Reconstr Surg Transplant Bull 1959;23:480-92.

9. Hidalgo DA. Lower extremity avulsion injuries. Clin Plast Surg 1986;13:701-10.

10. Mandel MA. The management of lower extremity degloving injuries. Ann Plast Surg 1981;6:1-5.

11. Corps BV, Littlewood M. Full-thickness skin replacement after traumatic avulsion. Br J Plast Surg 1966;19:229-33.

12. Farmer AW. Treatment of avulsed skin flaps. Ann Surg 1939;110:951-9. 
13. Coryllos E, Dabbert O, Tracey E, et al. Treatment of an avulsed skin-flap involving the circumference of the entire lower leg: a case report. Ann Surg 1960;151:437-40.

14. Sloan GM, Sasaki GH. Noninvasive monitoring of tissue viability. Clin Plast Surg 1985;12:185-95.

15. Moyer HR, Losken A. Predicting mastectomy skin flap necrosis with indocyanine green angiography: the gray area defined. Plast Reconstr Surg 2012;129:1043-8.

16. Phillips BT, Lanier ST, Conkling N, et al. Intraoperative perfusion techniques can accurately predict mastectomy skin flap necrosis in breast reconstruction: results of a prospective trial. Plast Reconstr Surg 2012;129:778e-788e.

17. Burnam JA. Intravenous fluorescein vascularity studies of a new technique: the subcutaneous pedicled extension flap. Arch Otolaryngol Head Neck Surg 1993;119:1329-36.

18. Lange K, Boyd LJ. The use of fluorescein to determine the adequacy of circulation. Med Clin North Am 1942;26:94352.

19. Thorvaldsson SE, Grabb WC. The intravenous fluorescein test as a measure of skin flap viability. Plast Reconstr Surg
1974;53:576-8

20. McCraw JB, Myers B, Shanklin KD. The value of fluorescein in predicting the viability of arterialized flaps. Plast Reconstr Surg 1977;60:710-9.

21. Myers B, Donovan W. An evaluation of eight methods of using fluorescein to predict the viability of skin flaps in the pig. Plast Reconstr Surg 1985;75:245-50.

22. Singer R, Lewis CM, Franklin JD, et al. Fluorescein test for prediction of flap viability during breast reconstructions. Plast Reconstr Surg 1978;61:371-5.

23. Losken A, Styblo TM, Schaefer TG, et al. The use of fluorescein dye as a predictor of mastectomy skin flap viability following autologous tissue reconstruction. Ann Plast Surg 2008;61:24-9.

24. Pearl RM. A unifying theory of the delay phenomenon: recovery from the hyperadrenergic state. Ann Plast Surg 1981; 7:102-12.

25. Morris SF, Taylor GI. The time sequence of the delay phenomenon: when is a surgical delay effective? An experimental study. Plast Reconstr Surg 1995;95:526-33. 